\title{
INFLATION AND MONETARY POLICY IN SEPTEMBER 2013
}

\author{
A.Bozhechkova
}

In September 2013, the Consumer Price Index (CPI) amounted to 0.2\% (against 0.6\% in September 2012), which is by 0.1 pp. higher than its value recorded in August 2013. Thus, the inflation rate in per annum terms, as seen by the results of the first 9 months of 2013, increased above 6.1\%. Over the first 23 days of October, the CPI amounted to $0.4 \%$. In spite of a slowdown in economic activity, the RF Central Bank has not reduced its target interest rate.

In September, the inflation rate in the Russian Federation accelerated: the Consumer Price Index (CPI), as seen by the month's results, amounted to $0.2 \%$ (against $0.1 \%$ in August 2013), whilst still remaining by 0.4 p.p. below its index for 2012. As a result, the inflation rate in per annum terms climbed to $6.1 \%$ (Fig. 1). The core inflation rate ${ }^{1}$ in September 2013 was $0.7 \%$, which is similar to its index for the same period of last year.

Prices of foodstuffs in September remained unchanged by comparison with August 2013 (Fig. 2). Prices of fruit and vegetable products continued to decline (from -11.3\% in August to -7.6\%). The growth rate of prices for granulated sugar became slower (going down from $4.4 \%$ in August to $1.1 \%$ in September), eggs (from $7.4 \%$ in August to $6.5 \%$ ). At the same time, the growth rate of butter prices increased (from $2.6 \%$ in August to $2.9 \%$ in September), as did that of prices for milk and dairy commodities (from 1.2\% in August to $2.7 \%$ in September), fish and seafood (from $0.7 \%$ in August to $1.2 \%$ in September). The growth rate of prices for bread and bakery products, as well as that of alcoholic beverages, amounted to $0.5 \%$ in September.

The growth rate of the prices and tariffs established for commercial services rendered to the population in September was $0.1 \%$, thus plummeting below its August level $(0.9 \%)$. Due to the start of the new school year, the prices for services in the education system increased significantly $(+3.8 \%)$. The growth rate of the housing and utilities tariffs in September amounted to $0.3 \%$. Growth was demonstrated by the prices for services in the sector of sports and physical culture $(+1.8 \%)$, entertainment $(+1.2 \%)$, personal consumer services $(+0.5 \%)$, medical services $(+0.4 \%)$. The prices of passenger transport services and out-bound tourism, on the contrary, dropped by $2.7 \%$ and $0.8 \%$ respectively.

1 The core consumer price index reflects the level of inflation on the consumer market after adjustment for the seasonal (prices of vegetable and fruit products) and administrative (regulated tariffs for certain types of services, etc.) factors. This index is also calculated by the RF Statistics Service (Rosstat).
In September, the growth rates displayed by prices of nonfood commodities amounted to $0.5 \%$ - similar to their August 2013 level. In this commodity group, the steepest upward movement was demonstrated by the prices of tobacco products - by $+3.0 \%$ (against $+2.0 \%$ in August), motor gasoline - by $1.5 \%$ (against $+3.1 \%$ in August), footwear $-0.7 \%$ (against $0.3 \%$ B August), clothes and underwear $-0.6 \%$ (against $0.3 \%$ in August), pharmaceuticals $+0.5 \%$ (against $+0.5 \%$ in $\mathrm{Au}$ gust), and those of radio and television sets $(+0.4 \%)$ (against $0.3 \%$ in August).

In October, the inflation rate sped up in response to a halt in the seasonal rapid decline of prices for fruit and vegetable products and a leap of the prices of eggs. Over the first 23 days of October, the CPI amounted to $0.4 \%$ (against $0.5 \%$ over the same period of 2012). As a result, the cumulative inflation rate since the year's beginning rose to the level of 5.2\% (against $5.7 \%$ over the same period of 2012). It should be noted that the leap of prices by 0.2 p.p. in the third week of October point to the possibility of the year-end inflation index rising above $6 \%$. The main factors working against the inflation rate's upward movement are the absence of a marked pressure of demand on the level of prices and the relatively favorable situation with regard to the crops of the main agricultural products.

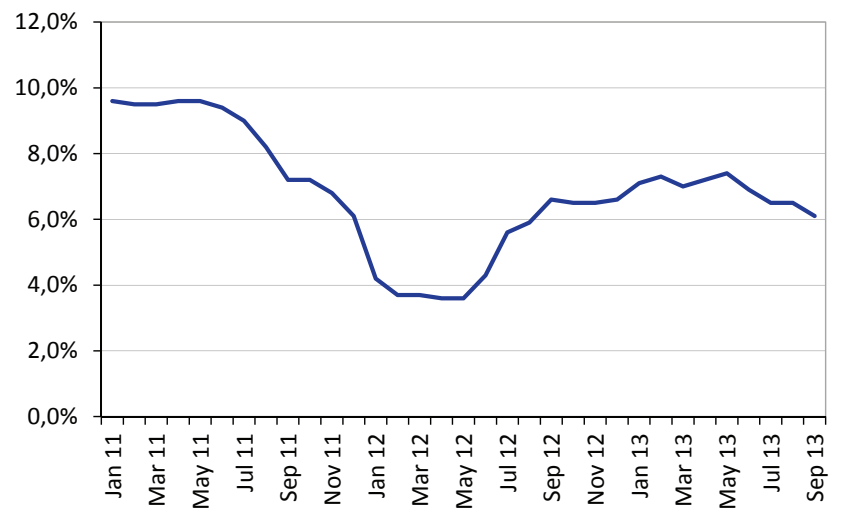

Source: Rosstat.

Fig. 1. The CPI Growth Rate in 2011-2013 (\% Year-on-Year) 
In September 2013, the broad monetary base increased by $2.5 \%$ to $\mathrm{Rb} 9,116.5 \mathrm{bn}$ (Fig. 3). Among the increased components of the broad monetary base one may point to the monies kept on commercial banks' correspondent accounts with the RF Central Bank (growth by $33.9 \%$ to $\mathrm{Rb} 1,097.8 \mathrm{bn}$ ), banks' deposits (growth by $9.0 \%$ to $\mathrm{Rb} 143.7 \mathrm{bn}$ ), and required reserves (growth by $0.9 \%$ to $\mathrm{Rb} 506.1 \mathrm{bn}$ ). The volume of cash in circulation, including the cash balances of credit institutions, displayed movement in the opposite direction (decline by $1 \%$ to $\mathrm{Rb} 7.369 \mathrm{bn}$ ).

The narrow monetary base (currency issued by the Bank of Russia plus required reserves) over September shrank by $0.9 \%$, amounting to $\mathrm{Rb} 7,875.1 \mathrm{bn}$ (Fig. 4).

In September 2013, the surplus reserves held by commercial banks ${ }^{1}$ rose by $30.4 \%$ to $\mathrm{Rb} 1,241.5 \mathrm{bn}$, while the amount of banks' repo debt increased by $14.1 \%$ - to a level in excess of $\mathrm{Rb} 2.5$ trillion. As of $28 \mathrm{Oc}$ tober, banks' repo debt amounted to $\mathrm{Rb} 2.3$ trillion. In a situation of continuing structural liquidity deficit in the banking sector, the interest rate in the interbank market ${ }^{2}$ in September was on the average at the level of $6.25 \%$ (against $6.11 \%$ in August 2013), thus increasing above its January index by $16.4 \%$ (against $5.4 \%$ in January). Over the period from 1 through 28 October, the average interest rate was $5.97 \%$ (Fig. 5). It is noteworthy that the decline of the interbank interest rate observed over the course of October occurred in part due to the auctioning, by the Bank of Russia, of threemonth loans secured by non-marketable assets at a floating interest rate, in the total volume of $\mathrm{Rb} 500 \mathrm{bn}$, the average cost of newly-issued debt being $5.76 \%$.

Thus, a considerable portion of the funding attracted by banks from the monetary regulator remains in the correspondent accounts of credit institutions kept with the Bank of Russia - a phenomenon reflecting a slowdown of the rate of crediting issued to the nonfinancial sector in conditions of stagnation in Russia's national economy.

As of 1 October 2013, the Bank of Russia's international reserves volume amounted to $\$ 522.6 \mathrm{bn}$, having shrunk since the year's beginning by $2.8 \%$ (Fig. 4). At the same time, the reserves backed by monetary gold over the month of September dropped by $\$ 2,3$ bn due to a downward adjustment of asset value.

As seen by the month-end results, the scale of currency interventions by the Bank of Russia in September was $\$ 3,178.4 \mathrm{~m}$ and $€ 214.96 \mathrm{~m}$, their purpose being to

1 The surplus reserves held by commercial banks at the RF CB are understood as the aggregate balance of their correspondent accounts, deposits with the RF CB and the bonds issued by the RF $\mathrm{CB}$ and held by commercial banks.

2 The interbank interest rate is the average monthly interest rate on overnight ruble-denominated interbank loans (Moscow Interbank Actual Credit Rate - MIACR).

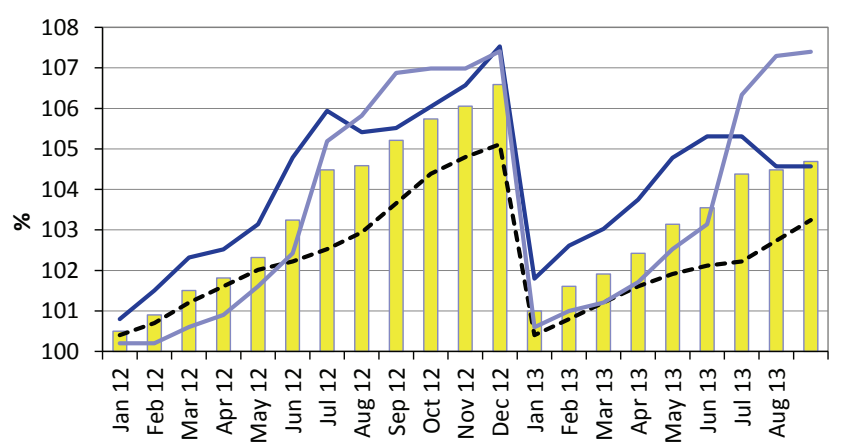

$\square$ the Growth Rate of CPI

- prices for non-food products

_ prices for food products prices and tariffs for paid services

Fig. 2. The CPI Growth Rate in 2012-2013 (as \% on December of Previous Year)

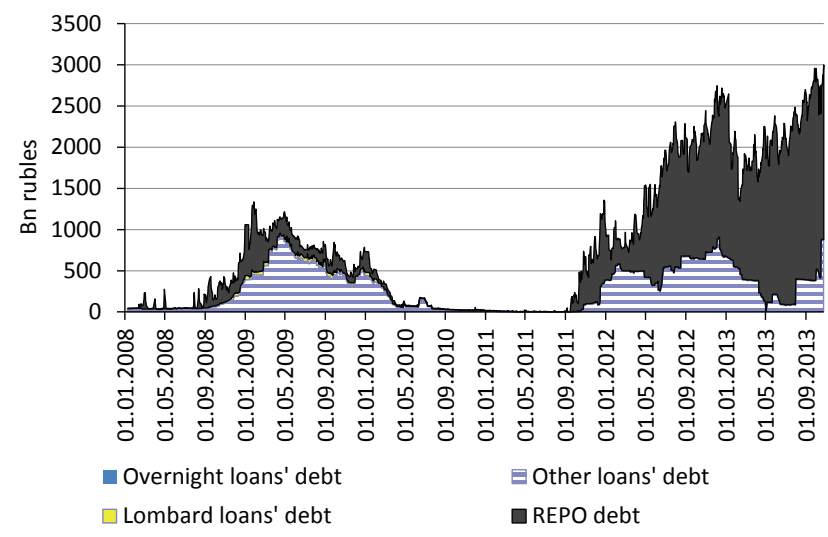

Fig. 3. The Movement of Commercial Banks' Debt to the Bank of Russia in 2008-2013

level down the volatility of the ruble's exchange rate (Fig. 6). Over that month, the state regulator repeatedly revised the boundaries of the bi-currency basket's floating corridor by 5 kopecks. As of 30 September, the boundaries of the bi-currency basket's floating corridor were set at $\mathrm{Rb}$ 32.30-39.30. Over the period from 1 through 25 October, the volume of foreign currency sales by the Bank of Russia amounted to $\$ 2,042 \mathrm{~m}$; at the same time, the regulator's purchases of foreign currencies in order to back up the replenishment or spending, by the Federal Treasury, of the RF sovereign funds denominated in foreign currencies amounted to $\$ 183 \mathrm{~m}$. The one-time upward adjustment of the bi-currency basket's corridor by 5 kopecks in October pushed the corridor boundaries up, to the level of $\mathrm{Rb}$ 32.35-39.35.

According to the Bank of Russia's preliminary estimates, net capital outflow from Russia in Q3 2013 increased to $\$ 12.9 \mathrm{bn}$, and on the whole for the first nine months of 2013 this index amounted to $\$ 48.1 \mathrm{bn}$, which is by $\$ 1.7 \mathrm{bn}$ higher than the same index for the first nine months of 2012. Over the period from January through September 2013, net capital outflow from 
the banking sector was $\$ 10.1 \mathrm{bn}$, while that from the other sectors amounted to $\$ 38.2 \mathrm{bn}$.

In September, the ruble's real effective exchange rate gained $1.3 \%$ (against $-1.8 \%$ in August 2013) (Fig. 7). As seen by the results of the first three quarters of 2013, the ruble's real effective exchange rate declined by $2.6 \%$.

Over the course of September, the exchange rate of the US dollar against the ruble dropped by $2.7 \%$, to $\mathrm{Rb} 32.3$. The decline of the euro's exchange rate against the ruble over September amounted to $0.7 \%$ ( $\mathrm{Rb}$ 43.6). In September, the average exchange rate of the euro against the US dollar amounted to 1.33. The value of the bi-currency basket over September shrank by $1.7 \%$ to $\mathrm{Rb} 37.4$. As seen by the results of the first 25 days of October, over that period the USD/ ruble exchange rate declined by $2.5 \%$, to $\mathrm{Rb} 31.7$., the euro/ruble exchange rate - by $0.2 \%$, to $\mathrm{Rb} 43.7$. As a result, the bi-currency basket's value increased by $1.3 \%$, to $\mathrm{Rb} 37.1$. The ruble's strengthening was boosted by the receding investors' fear that the US Federal Reserve System's third round of quantitative easing (QE3) was soon going to be halted. Thus, the average euro/ USD exchange rate for October amounted to 1.36. It should also be noted that the euro's strengthening occurred due to the end of recession in the eurozone, as well as the uncertainty with regard to the US government debt ceiling.

The Bank of Russia's monetary policy decisions taken in October 2013 were aimed in the main towards increasing the exchange rate's flexibility. From 1 October 2013, the Bank of Russia adjusted its exchangerate policy mechanism, and so the parameters of its currency purchase and sale operations on the domestic foreign currency market are now to be determined with due regard for the Federal Treasury's operations of replenishing or spending the RF sovereign funds denominated in foreign currencies. Thus, in particular, the volumes of currency purchase and sale operations carried on by the Bank of Russia on the domestic foreign currency market, which are determined with the purpose of leveling down the volatility of the ruble's exchange rate, will from now on be increased or downgraded by a figure equal to the actual volume of purchase (or sale) of foreign currencies by the Federal Treasury from (or to) the Bank of Russia, effectuated in order to replenish or spend the RF sovereign funds denominated in foreign currencies.

The recent adjustment of the exchange-rate policy mechanism is one of the components of the process of creating a framework for the transition to a floating currency exchange rate. This newly introduced measure will help to more or less neutralize the effect of the Federal Treasury's operations relating to replenish-

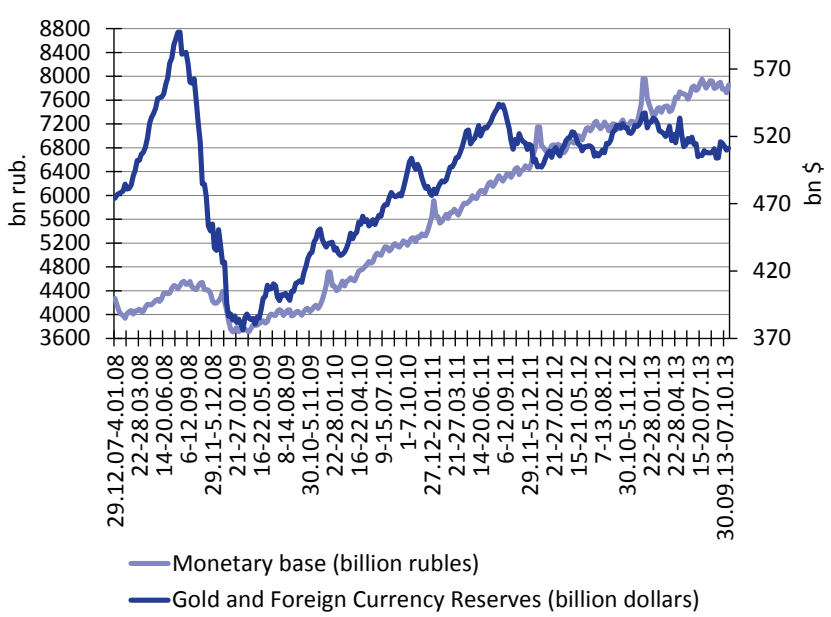

Fig. 4. Behavior of Russia's Narrow Monetary Base and Gold and Foreign Currency (International) Reserves in 2007-2013

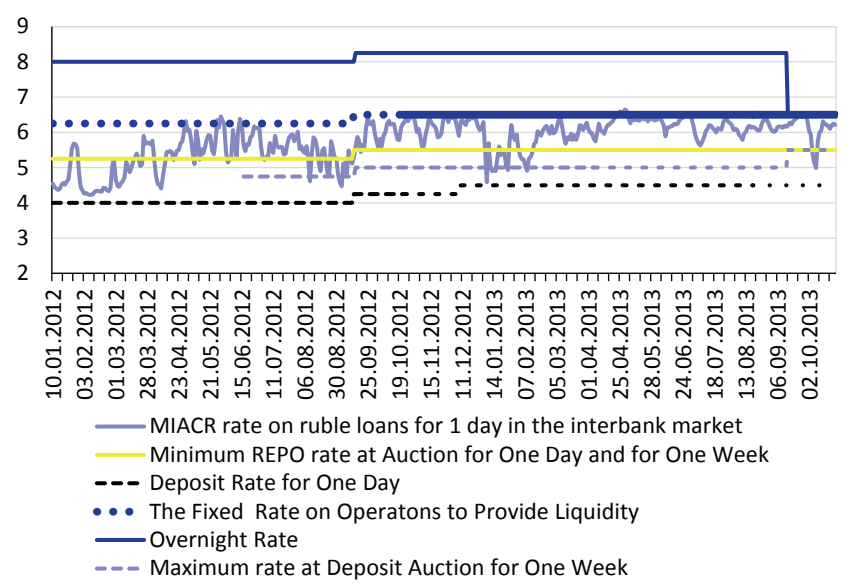

Fig. 5. The Bank of Russia's Interest Rate Corridor and the Interbank Market's Behavior in 2012-2013 (\% per Annum)

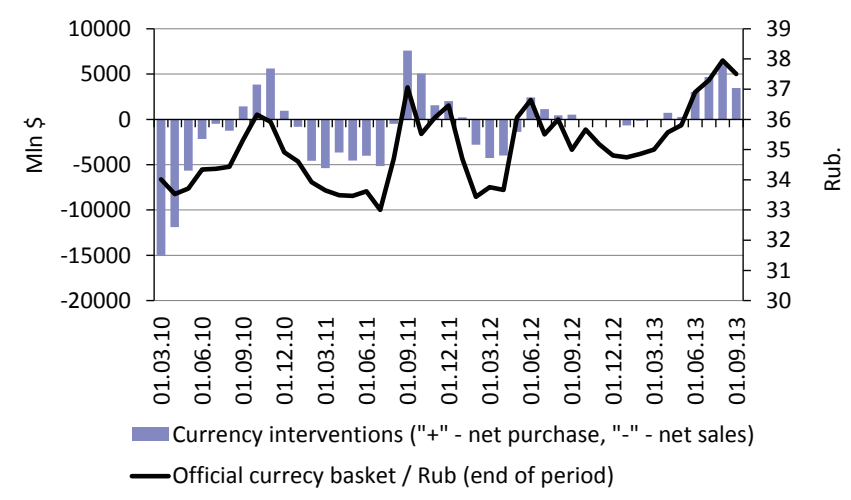

Source: RF CB; the author's calculations.

Fig. 6. The Bank of Russia's Currency Interventions and the Ruble Exchange Rate against the Bi-currency Basket in March 2010 - September 2013 


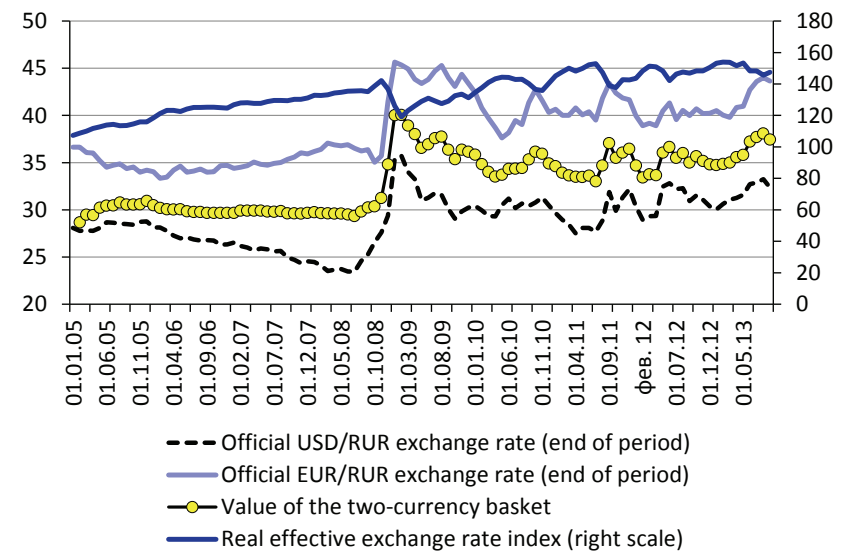

Source: RF CB; the author's calculations.

Fig. 7. Behavior of the Ruble's Exchange Rate Indicators in January 2005 - September 2013

ing or spending the RF sovereign funds denominated in foreign currencies on the banking sector's liquidity level.

On 7 October 2013, the Bank of Russia widened the neutral range of the operational bi-currency band to $\mathrm{Rb} 3.1$ from $\mathrm{Rb}$ 1, while keeping the general operating range of the bi-currency basket ( $R b \mathrm{7})$ unchanged.
It should be reminded that the neutral range is set inside the bi-currency basket's operating range. The currency exchange rate's fluctuations within that range do not prompt the regulator to resort to currency interventions. In the event of the exchange rate leaping beyond the neutral range, the Bank of Russia launches currency purchase (or sale) operations, whose volume increases as the exchange rate approaches the operating range's boundaries.

This decision will result in a decline in the volume of interventions conducted by the Bank of Russia in response to negligible fluctuations of the bi-currency basket's value. On the whole, such a decision is quite compatible with goal of gradually increasing the exchange rate's flexibility in order to strengthen the effect of the regulator's interest rate policy aimed at ensuring price stability.

From 21 October 2013, the Bank of Russia reduced the daily volume of its targeted currency interventions to $\$ 60 \mathrm{~m}$. This adjustment will result in increased sensitivity of the operational band borders to Bank of Russia interventions aimed at cushioning the excessive volatility of the ruble's exchange rate. Such policy alterations, all other conditions being equal, will reduce the scale of the Bank of Russia's direct presence on the domestic currency market. 